\title{
Brief History of Mass Spectrometry in Korea Related to the Establishment of the Korean Society for Mass Spectrometry
}

\author{
Hun-Young So* \\ Division of Metrology for Quality of Life, Korea Research Institute of Standards and Science, 1 Doryong-dong, Yuseong- \\ gu, Daejeon 305-340, Korea
}

Received November 14, 2010; Revised November 23, 2010; Accepted November 26, 2010

First published on the web December 15, 2010; DOI:10.5478/MSL.2010.1.1.001

Key words: KSMS, KMSG, History, Membership, Budget

In the early 1970 s, there were only a limited number of mass spectrometers in Korea and experts to whom you could ask about mass spectrometers. Two magnetic sector instruments were bought to Korea by the Japanese reparations as a result of the Treaty on Basic Relations between Japan and the Republic of Korea signed in 1965. One was operated at the Seoul National University (SNU) and the other was at the Ginseng and Tobacco Research Institute. It was too early to see any quadrupole mass spectrometer even at laboratories of developed countries. The first mass spectrometer installed for research purpose was the VG ZAB-E at the Professor MyungSoo Kim's (MSK) laboratory at SNU. It is fair to say that his laboratory was the only one in Korea where students could be trained as mass spectroscopist. In the middle of 1970s the Korean government had a loan from both IBRD and ADB to invest into modernization of analytical instruments to be used for educational purposes. But most of instruments became idle after several months or so due to lack of infrastructure needed for proper maintenance. It was the time when foreign currency was tightly controlled by the central government.

The main surge of mass spectrometers into Korea was some time before the Game of the Olympiad, Seoul in 1988 by installing modern analytical instruments needed to setup the Doping Control Center (DCC) established in 1986. Many of GC/MS were installed and scientists with analytical backgrounds were recruited. The DCC laboratory was headed by Dr. Jong-Sei Park (JSP). Many

*Reprint requests to Hun-Young So

E-mail: hys@kriss.re.kr of GC/MS were installed and a number of people understanding the instrument was kept on increasing.

As returning to Korea to work at the Korea Standards Research Institute (currently Korea Research Institute of Standards and Science) on August 1988, I visited Professor MSK at the SNU. He and I talked about research topics and the laboratory at Case Western Reserve University where both of us spent considerable times. It was during the Olympiad held from September 17 to October 2 in 1988. While discussing many matters with MSK, I suggested him an idea of establishing a society similar to the American Society for Mass Spectrometry (ASMS) in Korea for the advancement of mass spectrometry in Korea.

On 31 March 1989, seven people gathered at the meeting room of the Chemistry Department of the SNU to discuss about an organization for mass spectrometry. The participants were Professor MSK of the Chemistry Department of SNU, Professor Ji-Hwa Lee of the Department of the Applied Chemistry of SNU, Professor Kyung-Ryul Kim of the Department of the Oceanography of SNU, Professor Jong Man Yang of the Physics Department of the Ehwa Woman's University, JSP of the DCC, Mr. Sa-Moon Hong of the Korea Research Institute of Chemical Technology, and myself. The decisions made on the meeting became the seed of the current Korean Society for Mass Spectrometry (KSMS). Firstly, we agreed on the establishment of a voluntary organization, called the Korean Mass Spectrometry Group (KMSG). Secondly, we decided on membership open to any organization or person who are using and having 
interests in mass spectrometers while working at universities, institutes and industries in the fields of natural science, pharmaceuticals, medical science, engineering, environmental, etc. Thirdly, we organized a group. It was agreed that MSK, JSP, and HYS will serve as organizing committee until the first meeting of the KMSG. And then we set the activities of the KMSG: The Group will organize several seminars in a year, and will represent the mass spectrometry community in the international arena, and will provide training and workshops for the community.

It took more than a year to have the first KMSG meeting which was held at the Seoul National University on September 8, 1990. The logbook of the first meeting has names of 68 participants. But many of the students did not write their names. All together there were more than 80 participants in the room 102 at the Lecture Hall 28 of the SNU's Gwanak Campus.

The invitation letter sent to more than 120 people. The letter starts the invitation by saying "Dear Sir/ Madam. Recently the number of research projects using mass spectrometry, users of MS, and number of instruments are increasing remarkably. It was true that the rate of increase of MS was remarkable as the economical growth of the nation brought needs of better quality of life in every perspective". The announcement of the meeting was delivered by local sales agents of mass spectrometer vendors because it was not possible to list up the number of mass spectrometer operated in Korea and who are the representative users of those instruments. So the committee members asked to the sales agents to list up users and their addresses to make contact information. The first version of a mailing list has more than 120 people working at universities, research institutes and private companies. To make sure the news of meeting could be reached out to every MS users, each agent was asked to contact every user. Since then it became a tradition that sales agents are responsible to deliver the announcement of KMSG meeting. This tradition has been kept until early years of the present KSMS.

The first meeting had three lectures; Professor Dong Soo Lee of the Yonsei University, Professor MSK of the SNU, and Professor Dong Cheul Moon of the Chungbuk National University. The title of the first talk was "Potential of ICP/MS for the analysis for ultra trace elements in environmental samples" Professor Kim gave lecture on "Photodissocaition of p-nitrotoluene molecule ions in nanosecond time scale," and Professor Moon's was "Application of fast atom bombardment in bioanalytical chemistry".

After lectures, the participants discussed the future of the KMSG. There were endorsement on all related matters and the future plan to the three persons of the organizing committee of the KMSG. The three persons who started the organization of the first KMSG meeting were nominated to be members of the steering committee. It was also agreed to have more than three times of similar seminars in a year on Thursday or Friday and to cover every disciplines where mass spectrometers are used.

During the first several regular meetings, the expense of meeting was covered by fee of one thousand Won (approximately 10 dollars) which was barely enough to pay for gathering at a small restaurant after the seminar.

The second meeting of the KMSG was held on January 25, 1991 at Korea Research Institute of Standards and Science (KRISS) located at Daejeon. There were two lectures. The first one was given by Dr. Won Jo Chung at the Lucky Central Research Laboratory with the title of "Analytical methods using LC/MS". He is now a faculty member of Inha University at Incheon. The second speaker was HYS of the KRISS with the title of "Principles of Fourier transform mass spectrometry and analysis of polymers by laser desorption".

The third meeting of the KMSG was held on April 25, 1991 at the Johnson Auditorium of the KIST. There were seminars from two speakers. The first was by the late Dr. Song Ja PARK with the title of "Micro analysis of biological fluid using thermospray LC/MS". The second one was given by Dr. Stewart Cram for the US EPA with the title of "Environmental Pollutants analysis by mass spectrometry".

The fourth meeting of the KMSG was held on 11 September 1991 at the Korea Basic Science Research Center (currently the Korea Basic Science Institute) located at Seoul. There were two presentations. The first speaker was Dr. Joong Chul Choi (currently at the Dongkook University) with the title of "Principle and applications of tandem mass spectrometry". And the other speaker was Chuck B. Douthitt from Finnigan MAT. The title of his talk was "Historical development 
on isotope ratio mass spectrometry-from 1920 to present". The mailing list used for this meeting had 277 individuals. The number of contact points became more than double within a year of time.

In September 18, 1992, the KMSG had a special seminar at the Johnson Auditorium of the KIST at Seoul. Three speakers were chosen and invited among the participants of the International Conference on Biological Mass Spectrometry held at Japan during September 20-24 at Kyoto, Japan. They were Professors Fred McLafferty, R Graham Cooks, and Catherine Fenselau. Due to the financial difficulties, the KMSG took the opportunity of their coming to Japan, and ask them to visit Korea just before their trip to Kyoto. Four of learned society in Korea did sponsorship for the seminar. After estimating the total expense of the seminar, most of big sales agents of mass spectrometers in Korea were asked to contribute as sponsors to cover the expenses. They were Korean Chemical Society, The Analytical Society of Korea, Korea Microbiology Society, and Korea Pharmaceutical Society. The sponsorship was necessary because KMSG was a voluntary gathering with no authority of issuing receipts which could be accepted by tax authority. The receipts of sponsorship were issued by those established societies sponsored the seminar.

By spending so much energy for the success of the special seminar with limited human resources and financial support, members of the organizing committee were exhausted and had to find out a wiser solution to keep the activities on going. By rapid increase of scientific activities in Korea, most of the members changed their positions by promotions and relocations. And also the succession of leadership of the Group was not successfully done; so as to make activities become even slower.

In early 2000s, the leaders of MS community in Korea felt the need of society in a formal and legal manner. The KMSG renamed itself as the Korean Society for Mass Spectrometry (KSMS), although it had not been legally registered yet. An official website was opened for better communication of the society, www.ksms.org. To gain adequate momentum to maintain activities of KSMS, it was also important to have annual meetings in a regular basis. In early 2002, I took the responsibility to revitalize activities of the KSMS and organized the meeting with Drs. Yong-Hyeon Yim (YYH) and Byungjoo
Kim (BJK), which became the first unofficial regular meeting of the KSMS. It was held at a resort place located on western seashore, Anmyon Island, on $22^{\text {nd }}$ $23^{\text {rd }}$ October 2002 and had more than hundred participants even after a quite long period of inactivity. It was held in a workshop format to provide participants a general introduction on the principles and diverse applications of mass spectrometry. Some traditions of the KSMS have been started and handed down from this meeting. They include having a conference at a resort place on August to attract more participants to enjoy scientific communication as well as relaxation after conference. A dress code of casual or smart casual was highly recommended, therefore, to boost up unreserved discussion and interaction. Foods and drinks were provided free of charge thanks to the generous support of sponsors. It was quite clear from experience of the event that the MS community in Korea eager to have chances to learn and share scientific and technical information related with mass spectrometry.

To maintain regular activities of the society, a sound financial ground became essential. For that, registration of society as legal body was the most urgent matter. In the next regular meeting held at Yongpyong resort on $28-29^{\text {th }}$ August 2003, I was elected as the first official president of the KSMS chaired till 2005, articles were approved, and decided to register the KSMS as a legal person registered at the Ministry of Science and Technology. The registration was completed on April 2004. The first official KSMS meeting held at Pheonix Park resort, Pyungchang, on August 2004 took the form of a general academic conference by including symposium, poster presentations and workshops. The number of participants was over 200. The KSMS selects topic of particular interest every year and holds a winter symposium to promote in-depth coverage and discussion for specific areas of mass spectrometry starting from February 2005.

During my term of presidency, the firm establishment of the society and its traditions were the major focus. During terms of next two presidents, Drs. Jong Shin Yoo and Bong Chul Chung, the growth of membership and financial support by sponsors were really remarkable. Membership has grown roughly from 300 to 1300 and the budget has been increased 12 times during last 7 years. Such a remarkable growth could not be possible without sacrificing efforts of committee members, 
Hun-Young So

especially general secretaries. By the same token, enthusiastic supports of MS communities and sponsors in Korea are greatly appreciated.

Recently, KSMS went through a process of publishing the Mass Spectrometry Letters, under the leadership of a new president, Dr. Seung Koo Shin, which will set another milestone in the history of KSMS. This journal signifies how KSMS has grown up from a small study group to a fully grown society receiving global attention. 